\title{
AN EFFECTIVE METHOD OF TEACHING ENGLISH TENSE AND ASPECT THROUGH TIME ADVERBS
}

\author{
Chikako Takahashi ${ }^{1}$, \& Akemi Matsuya ${ }^{2}$ \\ ${ }^{1}$ Department of Nursing, Tokyo Junshin University (Japan) \\ ${ }^{2}$ Department of Human Sciences, Takachiho University (Japan)
}

\begin{abstract}
The English tense and aspect system is difficult for Japanese learners of English, partly due to the effect of Language Transfer and the difference in tense and aspect in the two languages: the Japanese inflectional ending 'teiru' can mark progressive, stative, and perfective meanings, and Japanese does not have a form corresponding to the English present perfect. We hypothesized that understanding the English time adverbs 'yet,' 'still,' and 'already' would help Japanese learners acquire the English tense and aspect system. We conducted an experimental lesson with Japanese university students using moving pictures to teach these adverbs. We found that these lessons resulted in a significant improvement compared to a control group.
\end{abstract}

Keywords: English tense, English aspect, English time adverb, SLA.

\section{Introduction}

In this paper, we aim to discover whether English time adverbs help Japanese adult learners of English understand the English aspectual systems. The difference between the aspectual systems in English and Japanese seems to hinder Japanese learners of English from acquiring the English aspect. English has three aspects: simple, progressive, and perfective, and the verb's inflection shows its aspect. In addition, Vendler $(1967)^{1}$ proposes that the sematic nature of each verb influences its inflectional form. On the other hand, Japanese aspect is semantically ambiguous. Verbs with the inflectional morpheme 'teiru' can be interpreted as progressive, past perfect, or present tense (see Teramura (1984) among others).

The purpose of our study is to prove the effectiveness of our material for English time adverbs both statistically and qualitatively. We adopted three time adverbs 'still,' 'already,' and 'yet,' as these adverbs are often confused by Japanese learners of English. We hypothesize that if the students can discriminate these time adverbs properly, their understanding of English aspect will improve.

\section{Previous studies}

According to Moriya \& Horie (2002), 'still' expresses 'a continuation of a situation' (1a). 'Already' indicates 'completion of an action' (1b). The adverb 'yet' and 'not' show that 'an expected change has not come at the present time '(1c).
a. It is still raining.
b. I have already finished today's homework.
c. We don't know yet how many people were killed.

The adverb 'still' goes well with the English progressive construction as both express that something is underway. In the sentence (1a), the continuous sense of 'still' plays a role of emphasizing the continuity of raining. In the case of $(1 \mathrm{~b})$, the completed meaning can be understandable without 'already.' Adding this adverb, the writer or the speaker can clarify the sense of completion. The adverb 'yet' in (1c) indicates that "We should have known how many people were killed at the time of the speech." Therefore, these three time adverbs play an important role to clarify or emphasize different English aspects.

\footnotetext{
${ }^{1}$ Vendler (1967) categorized English verbs into four types: activity verbs, stative verbs, achievement verbs, and accomplishment verbs. Activity verbs such as play and build do not have a starting point nor endpoint and indicate a change of state, therefore they can appear in progressive sentences. On the other hand, stative verbs such as like and know usually cannot appear in progressive forms as they show the continuation of a state. Achievement verbs, such as reach, focus on the endpoint. Their progressive forms indicate 'toward the end.'
} 
Cognitive Linguistics (CL) analyzes grammatical structures with diagrams of the items' core meanings. Langacker (2002) claims the core meaning of English progressive is "in the middle of something," as seen in (2), and proposes three types of progressive figures, as (3) shows.

(2) With respect to the perfective process $V$, the composite expression be $V$-ing defines a higher-order process that is limited to some internal portion of $V$, and construes the profiled states at a level of schematicity which renders them effectively identical.

Langacker (2002: 92)

(3) Langacker's Diagrams

Figure 1. Two Types of Process and Progressive.

a. Perfective Process Langacker $(2002,88)$

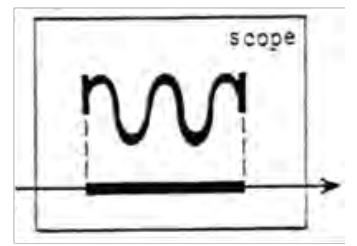

b. Imperfective Process Langacker $(2002,88)$

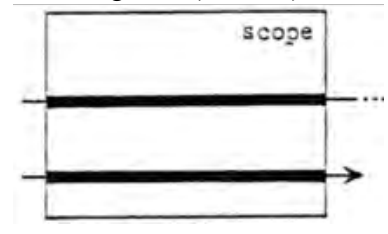

c. BE V-ING Langacker $(2002,92)$

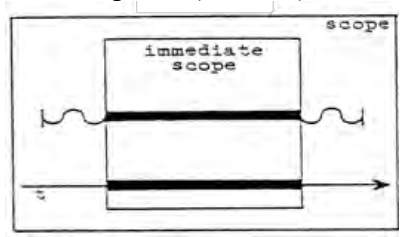

According to Langacker, the wavy line of the perfective process indicates 'change through time' (3a), while the straight line of the imperfective process represents 'constancy through time' (3b) (ll.34-36, p.87). As the above diagrams reveal, the immediate scope (IS) of the progressive construction resembles the imperfective process, as ( $3 \mathrm{~b})$ shows, since the be $V$-ing construction focuses some internal part of $V$, as (3c) depicts. Therefore, the core meaning of 'still,' 'a continuation of a situation,' goes quite well with the progressive and imperfective process, including simple aspect. On the other hand, 'already' and 'yet' are used to emphasize the perfective process since the key to the both adverbs is 'the completion of an action.'

Although these three time adverbs play an important role in understanding English aspects, Japanese learners of English often confuse them. Several researchers attribute such confusion to a different semantic domain between English and Japanese (Somiya 2007; Terashima \& Goto 2010). As for 'already' and 'yet,' the same Japanese word 'mou' can express both meanings. Another Japanese word 'mada' can be translated into 'still' or 'yet' depending on whether the sentence is affirmative or negative. If the sentence is affirmative, 'still' is used, while 'not yet' is used for a negative sentence. From the syntactic perspective, the Japanese inflectional ending 'teiru' can mark progressive, stative, and perfective meanings. Moreover, Japanese does not have a form corresponding to the English present perfect. This is another confusing factor for Japanese learners.

\section{Our research}

We created teaching materials for 'still,' 'already,' and 'yet' and conducted an experimental lesson to prove the effectiveness of our material. The participants are students enrolled in two Japanese universities. We divided them into two groups, the experimental group (28 students) and the control group (18 students). To the experimental group students we presented our original material (Figure 2), a moving picture showing the diagram representing a time arrow, the time of expected change, and the three time adverbs, each with their own movements. After presenting the material and a few explanations, we asked our students to answer questions later. We presented stories describing 12 situations and asked our research participants to choose the best sentence representing the whole situation out of four choices, each including one of the above time adverbs, 'still,' 'already, or 'yet.' This quiz is web-based, so that the students are allowed to answer the questions in their free time. To the control group students, we mentioned the dictionary definition of each time adverb. Later, we asked them to answer the same web-based questions as the experimental group students. Both students are also required to fill in why they choose the sentences.

\subsection{Moving picture diagram}

Figure 2 is the diagram of our teaching material. 'Not yet' does not reach the expected change, while 'already' has passed the line faster than expected. 'Still' moves throughout the time. 
(5) Teaching Material

Figure 2. Moving Picture Diagram.

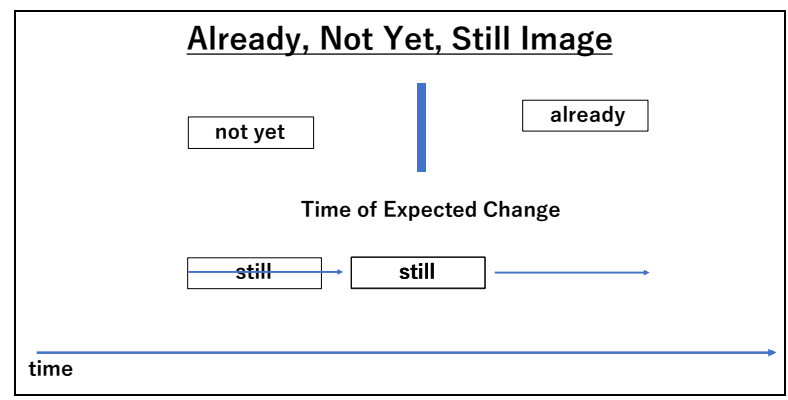

\subsection{Questionnaire}

The research participants were presented with 12 questions of the following form and required to choose one sentence matching the given situation.

(6) Sample of the questionnaire

My favorite place to go on the weekend is a bookstore with a nice cafe next door. Today is Saturday, so I hope to have time to go there and buy a new book about gardening. However, first I have to clean the house and write a letter to my grandmother.

(1) I am going to the bookstore already.

(2) I am not going to the bookstore yet.

(3) I am still going to the bookstore.

(4) I am not going to the bookstore anymore.

\section{Results}

First, we compared the grammatical competence of the two groups, based on the results of a TOEIC-style English test. According to the F-test to confirm the equal dispersion between the experimental group and the control group, the F-value is 0.22 , which is higher than significance level, 0.05 . That is, the two group's distribution is the same statistically. So, we can proceed with the t-test based on the two groups with the equal dispersion, as table 1 shows.

(7) Results of F-test

Table 1. Comparison of English Competence between the Two Groups.

\begin{tabular}{|l|r|r|}
\hline & Experimental Group & Control Group \\
\hline Average & 7.2962963 & 4.64705882 \\
\hline Variance & 3.06267806 & 4.24264706 \\
\hline Number of obs. & 28 & 18 \\
\hline Degree of freedom & 26 & 16 \\
\hline F-value & 0.72187906 & \\
\hline $\mathrm{P}(\mathrm{F}<=\mathrm{f})$ : one-sided & 0.22358041 & \\
\hline
\end{tabular}

\subsection{Test results}

In order to confirm the effectiveness of our material, we conducted a t-test. According to the t-test, we obtain the t-value, 0.00043 , which is lower than the level of significance, 0.05 . So, the null hypothesis that the average of the two groups are not different, can be rejected. In other words, the average of the experimental group is higher than that of control group.

(8) Result of $t$-test

Table 2. Comparison of the Test Results between the Two Groups

\begin{tabular}{|l|r|r|}
\hline & Experimental Group & Control Group \\
\hline Average & 7.2962963 & 4.64705882 \\
\hline Variance & 3.06267806 & 4.24264706 \\
\hline Number of obs. & 28 & 18 \\
\hline Pooled variance & 3.51219006 & \\
\hline degree of freedom & 42 & \\
\hline t-value & 4.56574749 & \\
\hline $\mathrm{P}(\mathrm{T}<=\mathrm{t})$ : one-sided & 0.0000215 & \\
\hline
\end{tabular}




\subsection{Descriptive analysis}

Based on the test results and students' written explanations, we categorized student's comments on each question into four types: (A) correct answer with understanding of time adverbs; (B) incorrect answer with understanding of time adverbs; $(C)$ correct answer without understanding of time adverbs; and (D) incorrect answer without understanding of time adverbs. We judged whether the participants understand time adverbs correctly from their writing. If their writing includes the proper time adverb(s) that are key to solving the question, we counted it as 'understanding time adverbs.' If the time adverb is not appropriate, we did not count it at all.

4.2.1. Overall results. $27.08 \%$ of the experimental group students arrived at their answers using their knowledge of time adverbs (table 3) while $7.87 \%$ of control group students utilized their knowledge to answer the questions (table 4). Among the experimental group students, $78.02 \%$ of those who understand time adverbs answered correctly. On the other hand, 58.82\% with the knowledge of time adverbs arrived at the correct answers in the case of the control group.

(9) Overall Result

Table 3. Experimental Group (28 participants).

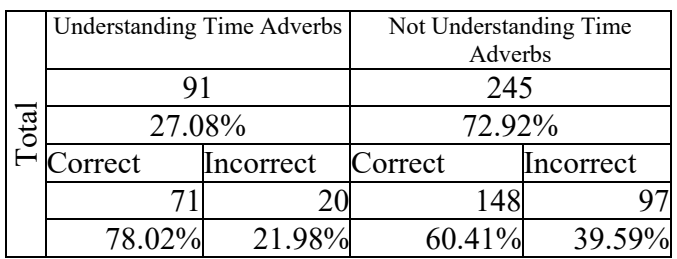

Table 4. Control Group (18 participants).

\begin{tabular}{|c|c|c|c|c|}
\hline \multirow{6}{*}{$\frac{\pi}{0}$} & $\begin{array}{l}\text { Unde } \\
\text { Time }\end{array}$ & $\begin{array}{l}\text { erstanding } \\
\text { e Adverbs }\end{array}$ & $\begin{array}{l}\text { Not Under } \\
\text { Time Ad }\end{array}$ & $\begin{array}{l}\text { standing } \\
\text { dverbs }\end{array}$ \\
\hline & & 17 & 19 & \\
\hline & & $7.87 \%$ & 92.13 & \\
\hline & Correct & Incorrect & Correct & Incorrect \\
\hline & 10 & 7 & 84 & 115 \\
\hline & $58.82 \%$ & $41.18 \%$ & $42.21 \%$ & $57.79 \%$ \\
\hline
\end{tabular}

Figure 3. Comparison of the Performances in Total.

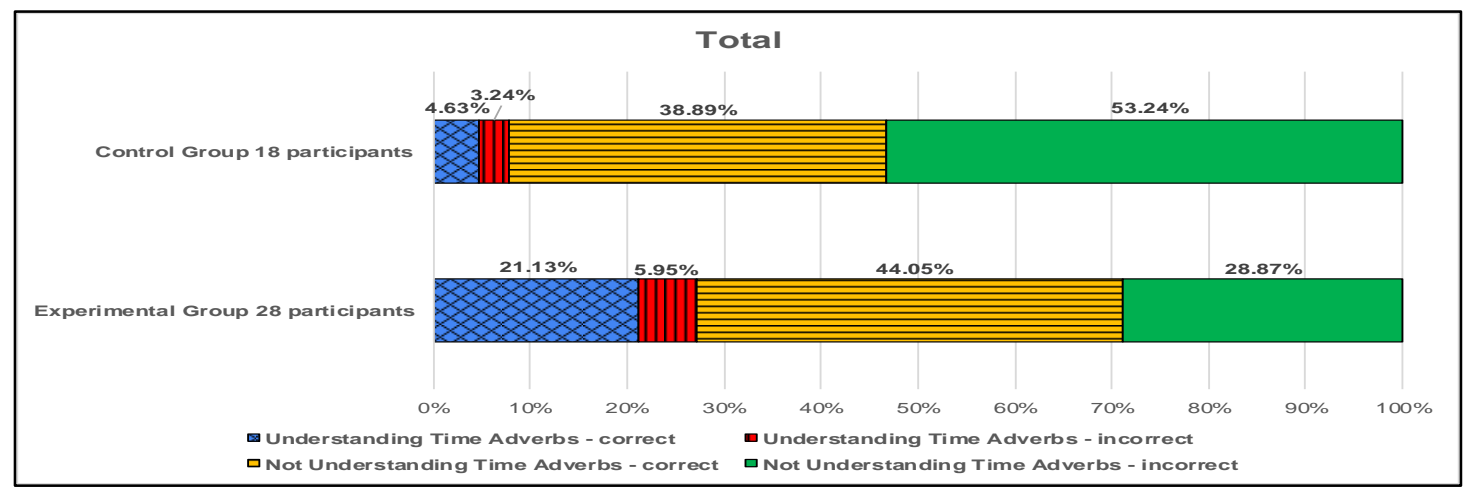

4.2.2. Individual cases. While the experimental group outperformed the control group in their understanding of time adverbs, in both groups, the majority apparently did so without using their knowledge of time adverbs. We believe that this can be attributed to properties of certain experimental items. In Q3, there are cues to the correct answer in the tenses: Mary was promoted, but an announcement will be made, suggesting that Mary got a promotion but the announcement has not yet been made public. In Q11, the correct answer, 2 , is the only one with a positive meaning and can therefore be linked to the positive meaning of the passage.

[3] For many years Mary has worked for a large railroad company. The company has never had a woman president. This week, Mary was promoted to president. Her promotion will not be made public until next month. Many reporters will want to write about the first woman president of the company, so she wants time to prepare for interviews.

1. Although she is still president, it has not yet been announced.

2. Although she has not yet become president, it has been announced.

3. Although she has finally become president, it has not yet been announced.

4. Although she is not yet president, it has not yet been announced.

[11] Some people in the US argue that libraries are a thing of the past and need to change or else get less government funding. They believe that students need to learn to use computers and that books are less important than they once were. However, many libraries offer free use of computers. They also have classes that teach students how to do research online. 
1. Libraries are already out of date.

2. Libraries are already helping students develop skills.

3. Libraries are still stuck in the past.

4. Libraries are not yet changing with the times.

(11) Results of Individual Cases

Table 5. Results of Q3.

Experimental Group

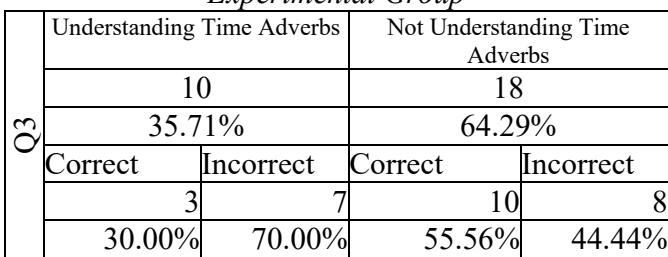

Control Group

\begin{tabular}{|c|c|c|c|c|}
\hline \multicolumn{5}{|c|}{ Control Group } \\
\hline \multirow{6}{*}{$\ddot{\sigma}$} & \multicolumn{2}{|c|}{ Understanding Time Adverbs } & \multicolumn{2}{|c|}{$\begin{array}{c}\text { Not Understanding Time } \\
\text { Adverbs }\end{array}$} \\
\hline & \multicolumn{2}{|c|}{2} & \multicolumn{2}{|c|}{16} \\
\hline & \multicolumn{2}{|c|}{$11.11 \%$} & \multicolumn{2}{|c|}{$88.89 \%$} \\
\hline & Correct & Incorrect & Correct & Incorrect \\
\hline & 1 & 1 & 9 & 7 \\
\hline & $50.00 \%$ & $50.00 \%$ & $56.25 \%$ & $43.75 \%$ \\
\hline
\end{tabular}

Table 6. Results of $Q 11$.

\begin{tabular}{|c|c|c|c|c|}
\hline \multicolumn{5}{|c|}{ Experimental Group } \\
\hline \multirow{6}{*}{$\overline{0}$} & Understanding & Time Adverbs & $\begin{array}{r}\text { Not Understa } \\
\text { Adve }\end{array}$ & $\begin{array}{l}\text { Inding Time } \\
\text { rbs }\end{array}$ \\
\hline & 2 & & 26 & \\
\hline & 7.14 & $4 \%$ & 92.8 & $6 \%$ \\
\hline & Correct & Incorrect & Correct & Incorrect \\
\hline & 1 & 1 & 15 & 11 \\
\hline & $50.00 \%$ & $50.00 \%$ & $57.69 \%$ & $42.31 \%$ \\
\hline
\end{tabular}

Control Group

\begin{tabular}{|l|r|r|r|r|}
\hline \multirow{2}{*}{} & \multicolumn{2}{|c|}{ Understanding Time Adverbs } & \multicolumn{2}{|c|}{$\begin{array}{c}\text { Not Understanding Time } \\
\text { Adverbs }\end{array}$} \\
\cline { 2 - 5 } & \multicolumn{2}{|c|}{0} & \multicolumn{2}{|c|}{18} \\
\hline \multicolumn{2}{|c|}{$0.00 \%$} & \multicolumn{2}{|c|}{$100.00 \%$} \\
\hline & Correct & Incorrect & Correct & Incorrect \\
\hline & 0 & & 9 & $50.00 \%$ \\
\hline
\end{tabular}

\section{Discussion and concluding remarks}

In our research, we tried to investigate whether English time adverbs will help Japanese learners of English understand the English aspectual system. We compared the performance of two groups: the experimental group and the control group. The statistical analysis reveals that the experimental group students outperform the control group students in terms of the test results. The overall descriptive analysis from their writings indicates the experimental group understands time adverbs better. However, the majority of the answers fall into the category 'correct answer without understanding time adverbs.' The individual cases reveal that the students used other cues to answer the questions, such as tense, or positive or negative connotations.

\section{Acknowledgements}

We would like to extend our acknowledgement to Dr. Linda Lombardi for her time and effort devoted to improving the quality of our research. This work was supported by JSPS KAKENHI Grant Number JP17K02948.

\section{References}

Langacker, R.W. (2002). Concept, Image, and Symbol: The Cognitive Basis of Grammar. Berlin, New York: Mouton de Gruyter.

Moriya, T. \& Horie, K. (2002).'Jikan kankeifukushi no bunpouka ni kansuru ichikousatsu' [Grammaticalization of Time-relationship adverbs: From the Perspective of Layering and Persistence], Proceedings of $2^{\text {nd }}$ Annual Meeting of the Japanese Cognitive Linguistics Association, pp.34-41.

Somiya, K. (2007). 'Eigo to Nihongo no Jisei Sou nit suite [ Tense and Aspect in English and Japanese],' Tokyo University of Foreign Studies Collection of Papers 73, pp.1-19.

Teramura, H. (1984). Nihongo no Shintakusu to Imi ll [Japanese Syntax and Semantics 11], Tokyo: Kuroshio Shuppan.

Teramura, T. \& Goto, K. (2010). 'New Development of English Teaching and Language Acquisition: through Thought Experiment of TENSE and ASPECT (1)' Annual Report of the Faculty of Education, Gifu University, Humanities and Social Sciences, Gifu University Bulletin, vol.58, No.2, pp.75-116.

Vendler, Z. (1967). Linguistics in Philosophy. New York: Cornell University Press. 